\title{
ACERCA DEL AMOR EN EL CARMELO DESCALZO: DIÁLOGO ENTRE TERESA DE JESÚS Y MARÍA DE SAN JOSÉ
}

\author{
MARÍA JOSÉ DE LA PASCUA SÁNCHEZ | UNIVERSIDAD DE CÁDIZ \\ CATEDRÁTICA DE HISTORIA MODERNA | ORCID iD: 0000-0003-2325-660X
}

\begin{abstract}
RESUMEN
La articulación de la representación del amor en torno a la poderosa antinomia amor sagrado/amor profano en la Alta Edad Moderna, canalizada a través de discursos y prácticas, precisa una profundización mayor de la que poseemos en el análisis de su génesis y de sus variables discursivas. Este estudio dirige sus objetivos a la investigación de su influencia y materialización práctica a través de los escritos de Teresa de Jesús y María de San José, dos escritoras carmelitas que hicieron del amor sagrado el centro de sus reflexiones y sus vidas.
\end{abstract}

PALABRAS CLAVE

Teresa de Jesús, María de San José, Reforma Carmelita, Discursos sobre el amor, Amor Sagrado, Alta Edad Moderna, Historia social y cultural.

\section{THOUGHTS ABOUT LOVE IN THE DISCALCED CARMELITE ORDER: DIALOGUE BETWEEN TERESA DE JESÚS \& MARÍA DE SAN JOSÉ}

\begin{abstract}
During the Early Modern Age, the representation of love was articulated around the powerful antinomy of sacred love vs. profane love. This representation, channelled through several discourses and practices, requires a more profound analysis especially around its genesis and its discursive variables. This study focuses on the investigation of its influence and practical materialisation through the writings of Teresa de Jesús and María de San José, two Carmelite writers who made 'Sacred love' the center of their reflections and their lives.
\end{abstract}

\section{KEYWORDS}

Teresa de Jesús, María de San José, Carmelite Reform, Discourses about Love, the Sacred Love, Early Modern History, Social and cultural History.

\footnotetext{
1 Investigación integrada en el proyecto "Espacios de conocimiento, cultura y agencia femeninas en el Mundo Moderno y Contemporáneo (siglos XV-XX)", ref. PGC2018-097445-B-C21 del Plan Nacional de Investigación del Ministerio de Ciencia, Innovación y Universidades.
} 


\section{MARÍA JOSÉ DE LA PASCUA SÁNCHEZ}

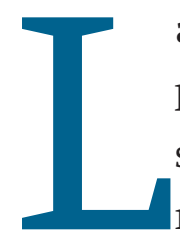

a perspectiva, que subraya el "peso" de la cultura en la vivencia del amor, no siempre ha estado presente en la Historia. El interés por trazar las fronteras entre la sexualidad animal y el amor humano es un hecho reciente en las Ciencias Humanas y Sociales, al menos como preocupación general, y es preciso esperar a finales del XX para ver nacer la necesidad del estudio del erotismo y del amor como realidades biológicas y culturales a la vez. Es entonces cuando ambos se perciben como formas derivadas, aunque distintas, del instinto sexual, es decir, cristalizaciones, condensaciones sublimaciones o proyecciones culturales más o menos totalizantes, del dominio del sexo. Esta orientación cultural está en auge desde la década de los setenta del siglo XX, justamente cuando se difunde, también con éxito, una visión puramente biologicista, la química del amor, a partir de los estudios de la neurociencia ${ }^{2}$; visión, esta última, al día de hoy en retroceso merced a los avances en el conocimiento de la dinámica de la psique. Pues bien, la historiografía del amor prenderá al compás de ambas en esas últimas décadas del siglo XX en la confluencia de varias disciplinas y áreas temáticas.

El nuevo interés por el amor nacido en la encrucijada que provoca en la historia social la aparición de nuevos protagonistas (el sujeto, las mujeres, los grupos marginales), nuevas perspectivas (el giro cultural, la historia de la vida cotidiana), nuevas metodologías (microhistoria) y nuevas fuentes (documentos personales), se acompaña de los primeros debates en torno a la idea del amor y sus cambios a lo largo de la historia. Desde estos primeros esbozos que fraguaron iniciales teorías, todavía algo desorientadas por adheridas a una noción esencialista ${ }^{3}$, el reconocimiento de la deuda cultural existente en la vivencia del amor y la concepción de este como algo aprehendido no ha hecho más que ampliarse y, con él, los objetivos de los historiadores se han ido fijando de forma creciente alrededor de las representaciones sociales construidas temporalmente que, como "moldes" guían la identificación, la verbalización y la práctica de las emociones. Aun así y a pesar del tiempo transcurrido que ha visto multiplicar los análisis, queda camino por recorrer; un camino que no siempre se vislumbra fácilmente. La problemática y las correcciones sucesivas a los primeros planteamientos han ido incorporándose a nuestras perspectivas teóricas y prácticas al tiempo que los resultados de investigaciones se han ido multiplicando. La mayoría

2 FISCHER, Helen E. Anatomía del amor. Historia natural de la monogamia, el adulterio y el divorcio. Barcelona, Círculo de Lectores, 1993.

3 DE LA PASCUA, Ma José. Regulación de los afectos y cultura del amor en la sociedad hispana de la época moderna, IGLESIAS, J.J., PÉREZ, Rafael M., FERNÁNDEZ, Manuel F. (eds.), Comercio y cultura en la Edad Moderna. Sevilla, Editorial de la Universidad de Sevilla, 2015. pp. 233-255. 
de ellas han centrado el análisis en dos modalidades de amor; el sexual o el amor de pareja y el amor paterno filial. Los estudios realizados han abrazado la temática de los discursos, generando en los últimos años un buen número de trabajos sobre los estilos de la Erotika, según la expresión socrática de "las cosas del amor", y con el apoyo de una base heurística constituida por obras de carácter moral y literatura sentimental. Los estudios académicos también se han ocupado de las prácticas, especialmente de las transgresoras con el modelo de amor dominante, investigadas en diferentes periodos históricos a partir de la documentación judicial, procedente de tribunales civiles y eclesiásticos. El análisis de estas ha ofrecido un panorama diverso de contextos relacionados con los comportamientos en torno al sexo y a las relaciones amorosas vehiculadas a través de conflictos y violencias ${ }^{4}$. En ambos campos, el de los discursos comprendidos en la pluralidad aglutinada en torno a diferentes modelos relacionados, interdependientes y jerarquizados, tal y como se hallan presentes en un determinado contexto cultural y el de las prácticas, no sólo las que generan algún tipo de respuesta punitiva, sino también de aquellas otras, la mayoría, insertas en la cotidianeidad del vivir, es preciso avanzar afinando análisis y reflexiones. Me remito aquí, respecto a este último punto, a lo escrito ${ }^{5}$, porque en esta ocasión me centraré en el amor místico y en la formulación del lenguaje del amor inscrito en él como variable de uso de la tópica cultural amorosa de la temprana edad moderna. Asimismo, pretendo analizar las interrelaciones entre amor místico y amor profano que la práctica de este modelo ofrece en dos escritoras religiosas del XVI hispano y en la aportación que sus interpretaciones y el lenguaje con el que el amor es descrito, ofrece al discurso amoroso en la España áurea. Realizando todo ello, desde la consideración que tanto la noción de amor místico, de procedencia neoplatónica por utilizar una referencia general distintiva, como su representación y expresión bajo la fórmula del Amor sagrado, se integran en uno de los estilos florecientes en los que se enmarcan las prácticas amorosas del periodo.

La elección de los inicios de la modernidad como contexto ${ }^{6}$ tiene que ver con la necesidad de comprender las razones por las que el discurso sobre el amor se sitúa permanentemente a lo largo de la época moderna en la disyuntiva de amor bueno/ amor malo, que se corresponde, en parte, en su versión culta con amor sagrado/ amor profano, y qué idea del amor

\section{Ibidem, pp. 239-244}

5 Ibidem, Pp. 244-255 y DE LA PASCUA, Ma José. Las incertidumbres del corazón: la Historia y el mundo de los afectos, Cuadernos de Historia Moderna. (Universidad Complutense de Madrid), 2015, XIV, 5-8, 151-172.

6 DE LA PASCUA, Ma José. Amor/Desamor a comienzos de la Edad Moderna; ¿Universo de emociones femeninas o política emocional?, BARTOLOMÉ, Juan M., GARCÍA, Máximo, SOBALER, Ma Ángeles (eds.), Modelos culturales en femenino. Siglos XVI-XVIII. Madrid, Sílex, 2019, 133-183. 
abriga uno y otro concepto. Concretamente si son dos conceptos tan enfrentados como aparecerán en la tratadística moral sobre el matrimonio de los siglos XVI y XVII o existe una filiación entre ambos, fruto de la herencia cultural y el lenguaje común que conforma el imaginario amoroso.

\section{EL AMOR MÍSTICO: FUENTES Y LENGUAJE}

El amor místico representa el grado supremo de una de las fórmulas dominantes en los modelos de amor en la Modernidad, el amor sagrado, que en el discurso se presenta habitualmente hermanado, aunque en franca antinomia con el amor humano o profano ${ }^{7}$, del que se figura su opuesto ${ }^{8}$. La oposición, sin embargo, no parece tan sustancial, no si se analiza el discurso de destacados pensadores del modelo. La contaminación del pensamiento religioso con el de filósofos y poetas clásicos y medievales es una realidad que dota de complejidad y diversificación de herencias a la idea del amor occidental y no permite divisiones tajantes.

En la Plena Edad Media aflora un nuevo producto cultural cuyo origen aún siembra de discusiones el panorama académico: se trata del, para algunos mal llamado, modelo de "amor cortés" 9 . Nos situamos en el siglo XII cuando es observable una reactivación del pensamiento del amor hasta entonces desconocida; reactivación que camina de la mano de una cultura femenina instalada en las cortes feudales en el contexto de los cambios económicos y sociales que tienen lugar en el Occidente europeo durante la Plena Edad Media. Esta innovación cultural va asociada a un grupo social nuevo, al menos en su estatus y funciones: la caballería cortesana. Aunque según Arnold Hauser estos caballeros no descubren el amor, si dotan su representación de una expresión novedosa al contemplarlo como fuerza ética y canal de la experiencia más profunda de la vida. El amor se convierte en este mundo cortesano en principio educativo superior y se espiritualiza al tiempo que el lenguaje amoroso se erotiza y se impregna de

\footnotetext{
7 Una obra emblemática es la de Tiziano, "Amor sacro e amor profano (1515) y en nuestra literatura el poema que Lope dedica a María Magdalena, referente en los dos tipos de amor: "Los bellos ojos y el desdén tirano/En gracia y hermosura peregrino/Que mataron mejor de amor humano/Y lloraron mejor de amor divino", LOPE DE VEGA (1615), Rimas sacras de..., con cien octavas a la Vida de la Magdalena. Lisboa, Henrique Valente, 1658, pp. 69-97.

8 Para O. Paz, si en Oriente el amor fue pensado dentro de la tradición religiosa, en Occidente, al contrario, el amor fue imaginado. PAZ, Octavio. La llama doble. Amor v erotismo. Barcelona, Seix-Barral, 1993, p. 36.

9 Expresión dada por Gaston Paris, en 1880 al amor entre Ginebra y Lancelot (Chrétien de Troyes, Le Chevalier de la Charrette) y generalizada para denominar las ideas del amor que surgen en las cortes nobiliarias y reales de Francia desde finales del XI, ZUMTHOR, Paul (1972), La courtoisie, Essai de poétique médiévale. Paris, Seuil.
} 
sensualidad $^{10}$. Creación cultural de los poetas que toman al amor como ideal de vida superior y, a la vez, como producto estético y ascético elaborado, supone, entre otras manifestaciones, una inversión del rol de la mujer aupada a "dama" objeto de devoción y aparente sujeto de poder amoroso, aunque se viene subrayando su carácter virtual ${ }^{11}$. La significación del amor, marcada por un ideal de vida de perfección, se aleja de las funciones meramente sexuales y reproductivas, aquellas que precisamente Aristóteles había señalado como propias. La influencia del platonismo, entre otras, ha sido destacada por los expertos y desde comienzos del siglo XX críticos literarios e historiadores han debatido acerca de las distintas teorías sobre su origen. Desde la que subraya que su peculiaridad se halla en el mero traslado de las fórmulas de vasallaje feudal del señor a la dama, a la que enfatiza sus vínculos con la literatura clásica latina, sus deudas con las canciones populares o con la poesía cortesana islámica. Sobre todas ellas se han planteado objeciones y argumentos a favor ${ }^{12}$; pero me interesa destacar una de las teorías sobre la que ha gravitado la discusión, la que plantea vínculos entre el fine amor (amor perfecto) y la espiritualidad cisterciense.

Los expertos reconocen, en general, una influencia de la poesía clerical latina medieval sobre la lírica amorosa cortesana. Pero, al tiempo, matizan estos préstamos al considerar que no puede afirmarse que el concepto del amor caballeresco en su conjunto haya sido forjado por los clérigos, sea producto de los movimientos ascéticos del siglo XII o simple extensión de la caritas divina ${ }^{13}$. En opinión de Hauser, se trataría más bien de fenómenos paralelos, hijos de un mismo contexto de crisis de las formas feudales e irrupción de realidades nuevas, que hacen emerger un espíritu individualista y una cultura intelectual y libresca que se acompañan de un arte de vivir en el que se aúnan la elegancia moral y la de las formas de trato social y personal, amparadas en un concepto nuevo que surge: el de cortesía. Ambos procesos culturales serían síntomas de la revolución espiritual general y compartirían influencias ${ }^{14}$.

10 HAUSER, Arnold. El romanticismo de la caballería cortesana, en Historia Social de la Literatura y el Arte. Barcelona, Labor, tomo I, 1993. pp. 143-289.

11 Parte de la crítica insiste en que no supone un cambio significativo en la situación de las mujeres, DUBY, Georges. El modelo cortés, Historia de las Mujeres II. Edad Media. Barcelona, Círculo de Lectores, 1993. pp. 301-319.

12 HAUSER, A., El romanticismo de la caballería, op. cit., PP. 149-289.

13 ZUMTHOR, P., La courtoisie, op. cit.

14 HAUSER, A., El romanticismo de la caballería, op. cit. 
A pesar de los matices a la teoría sobre un posible origen religioso del amor cortés, no parece haber duda de la proximidad de ambas realidades culturales y de que se trata de un modelo de amor en el que el énfasis se coloca en la espiritualidad. Aún más que la expresión fine amor con la que se caracteriza al amor cortés tiene una carga ética indudable. Para autores como David Burnley el significado cualitativo de la expresión que traduce el amor perfecto, incorpora las característica de unión de afecto y voluntad tomada de la teoría de la amicitia $^{15}$, orientando decididamente esta expresión hacia categorías morales. En rigor, según el mismo, al definir el amor por una cualidad un tanto abstracta, la expresión fine amor no se dirige a ningún tipo particular de relación sino a cualquier relación amorosa entre seres humanos que alcance un grado de excelencia. De esta manera, la aplicación del término no se debe decidir en función de si es sexual o divino, marital o extramarital o a partir de una oposición entre amor puro o profano, porque la esencia de su significado se encuentra en los movimientos del alma, en la calidad y la intensidad del amor en sí mismo $^{16}$. El énfasis, de acuerdo con esta teoría, quedaría desplazado desde la contraposición habitual, amor sagrado/amor profano, a un territorio simbólico hasta entonces no explorado, el que distinguiría entre amor perfecto y el pseudo-amor.

Para Johan Huizinga, un historiador que analizó mucho y bien el tema, cuando en el siglo XII los trovadores ubicaron el deseo insatisfecho en el centro de la concepción poética del amor, el espíritu medieval dio un giro importante ya que, por vez primera, un ideal amoroso se desarrollaba sobre una base negativa. En el amor cortés, como novedad, el deseo insatisfecho se convierte en el tema esencial, creándose un modelo de relación erótica capaz de absorber aspiraciones éticas de toda índole, sin por ello renunciar a su conexión con el amor sensual $^{17}$.A mayor abundamiento un ejemplo puede ilustrar la idea que se plantea sobre las exigencias de carácter espiritual que pesan en el verdadero amor y su independencia del objeto-sujeto al que va dirigido. Se suele citar el Roman de la Rose como enciclopedia del amor cortés, en las variantes que ofrecen los dos poetas que intervienen en su creación, Guillaume de Lorris y Jean de Meun. Pues bien, también puede traerse a colación otro texto, el Breviari d'amor, escrito apenas algunos años después, en 1288, por el jurista

15 La noción de amistad (philia procedente del verbo plileîn, en griego, "querer"), posee en origen una significación más amplia de la que se le otorga en la actualidad pudiendo traducirse por todo tipo de relación basada en lazos de amor y afecto. En su desarrollo discursivo durante la Edad Media es notable la influencia de Aristóteles (Ética a Nicómaco, libros VIII y IX) y de la Laelius Amicitia de Cicerón.

16 BURNLEY, David. Fine amor. su significado y su contexto, BASARTE, Ana, DUMAS, María (eds.), Nueve ensayos sobre el amor $\gamma$ la cortesía en la Edad Media. Buenos Aires, Editorial de la Universidad de Buenos Aires, 2021. pp. $218-253$.

17 HUIZINGA, Johan. La estilización del amor, en El otoño de la Edad Media. Madrid, Alianza, 1978. 153-170. 
Matfre Ermengaut. En él, de carácter enciclopédico también, el autor no trata de reducir todo el amor a Eros, sino definir el lugar y la legitimidad de Eros en una clasificación cuyas raíces son el amor a Dios en y por su creación. En dicha obra es perceptible la intención de una síntesis entre el amor a Cristo (la caridad) y la pasión amorosa. Según la genealogía del amor, reflejada en la miniatura del "árbol del amor" contenida en el Breviari d'amor, existirían dos tipos de amor; el fuego del Espíritu Santo en cuyo abrazo se aman el Padre y el Hijo y que es un amor creador y el amor creado que es la pasión humana ${ }^{18}$.

Más allá de los datos empíricos que pueden aportar diferentes textos, la vigencia, en esta época de efervescencia del modelo de amor cortés, de una idea del amor fijada sobre la sublimación del deseo no satisfecho, presta fuerza al intento de llevar la hermandad entre el amor divino y el amor humano más allá de lo que algunos autores reconocen.

Fenómeno paralelo, la reflexión sobre el amor, tradicionalmente presente en la teología bajo la modalidad del amor a Dios, se hace, asimismo, muy frecuente a partir del siglo XII en los ambientes de renovación espiritual y religiosa. Una figura destacada y autor seminal es Bernardo de Clarivaux ${ }^{19}$, considerado padre de la mística. Aunque E. Gilson en su biografía sobre el monje matiza la teoría que concede ascendencia de su concepción del amor en el modelo del amor cortés, no hay duda que la difusión de su pensamiento y escritos impregnaron el lenguaje amoroso de los poetas y los místicos Su influencia fue notable en Elredo de Rieval (1110-1167), asimismo monje cisterciense y autor de un tratado teológico sobre amor (De Speculo Caritatis) y otro sobre la amistad espiritual (De spiritali amicitia) ${ }^{20}$, en realidad, dos partes de una misma obra, dedicada la primera al amor a Dios y la segunda al amor humano.

De la amistad espiritual de Elredo de Rieval, está inspirada en la obra de Cicerón (Laelius Amicitia), fuente dominante de las reflexiones sobre el amor-amistad en la Edad Media, tratando sobre su concepto, diferentes tipos, así como del proceso de aceptación de alguien como amigo. En el primer diálogo, Elredo se centra en el análisis de la naturaleza de la

18 ZINK, Michel. Un nouvel art d’aimer, L’Art d'aimer au Mopen Age. Paris, Éditions du Filin, 1997. 7-70.

19 Dante elige a san Bernardo como guía para su viaje simbólico al considerarle el maestro de la mística, expresando con ello la opinión de sus contemporáneos ya que, si bien no fue ni el primero ni el único en elaborar una teoría sobre el éxtasis, si fue autor de la síntesis doctrinal más completa y fuente para las generaciones futuras, GILSON, Etienne. La théologie mystique de Saint Bernard. Paris, J. Vrin, 1934.

20 FALVINO, Sergio. Aelredo de Rielvaulx y su mística de la amistad: algunas consideraciones sobre la importancia de la afectividad en el medievo [en línea]. Stylos, 2013, 22. Disponible en: http://bibliotecadigital.uca.edu.ar/repositorio/ revistas/aelredo-rievaulx-mistica-amistad.pdf [consultado en 28 de octubre de 2020]. 
amistad, aunque avanzando hacia la construcción de una noción de amistad que, según señala, nace, crece y termina en Cristo; noción que, dicho sea de paso, de alguna manera cristianiza la versión clásica del amor como impulso hacia la perfección, presente en Sócrates y Platón, y se halla materializada en el fine amor cortés. En el segundo diálogo y al enumerar los frutos de la amistad, para los que sigue a San Bernardo ${ }^{21}$, el autor se inspira en el Cantar de los Cantares de Salomón, concretamente en el primer poema del mismo que comienza con "Béseme con besos de su boca", haciendo suya la doctrina de los "tres besos", representación del triple progreso del alma en su camino hacia la perfección. El destino es Dios, de forma que la amistad humana - el primer beso- sería el peldaño previo para llegar al beso de Dios, de lo que resulta que la amistad humana y la divina, ambas formulaciones del amor, se integran en un mismo proceso. El tercer diálogo trata de la selección de los amigos y de las características de la amistad. Pero lo que interesa destacar para nuestro análisis es que la obra de San Alfredo estuvo muy difundida en los ambientes monásticos y a partir de la misma se asentó en el pensamiento occidental la conexión ineludible entre amor y amistad, amistad humana, amistad espiritual y amistad divina, al tiempo, que la presencia del Cantar de los Cantares -la fuente de su inspiración y de la de San Bernardo-, quedó establecida como obra de referencia en el lenguaje del amor ${ }^{22}$. Son estos dos aspectos claves sobre las que reposa la vivencia del amor místico.

Al tiempo que los comentarios sobre el Cantar de los Cantares cobraban protagonismo y su lenguaje entraba en la mística, la tratadística espiritual profundizaba en los matices diferenciales de las naturalezas del amor sagrado y del amor profano. La palabra amor se hacía explícita en los títulos de un buen número de libros espirituales y entre los publicados o escritos en los reinos de España recuperamos casi medio centenar editado, en su mayoría, entre 1543 y $1687^{23}$. Un rastreo a vuela pluma por algunos de sus títulos, especialmente entre los pertenecientes a los siglos XVII y XVIII ${ }^{24}$, proporciona evidencias de la influencia del lenguaje encendido del Cantar de los Cantares en la vivencia es-

21 Bernardo de Claraval escribió una veintena de sermones sobre el Cantar de los Cantares, glosando algunas de sus frases más destacadas: Sobre el beso en los pies, las manos $\gamma$ la boca (s. III) o Que me bese con besos de su boca (s. VII), contribuyendo a la difusión de la misma.

22 El Cantar de los Cantares capturó la atención de comentaristas y artistas desde finales del XII, sirviendo de inspiración para las miniaturas de manuscritos, TUCHSCHERER, Jean-Michel. The illustrations of the Song of Songs in the Bible moralisée de Saint Louis. Tesis Doctoral, McGill University, Montreal, Canada, [en línea]. 1996. http://centralbac-lac.gc.ca/.item?id=TC-QMM-40269\&op=pdf\&app=Library\&ofCanada [consultado el 15 de octubre de 2020]

23 Se localizan 44 títulos repartidos para los tres siglos. Extraigo los datos del catálogo de ANDRÉS, Melquíades. Historia de la mística de la Edad de oro en España $\gamma$ América. Madrid, BAC, 1994. pp. 153-207.

24 La primera versión del Cantar en castellano la hace fray Luis de León en 1565. 
piritual $^{25}$. Pero no es sólo el lenguaje del amor lo que muestra la glosa de San Bernardo sobre el Cantar, sino también la idea convergente del camino del amor como un camino de perfección sintetizada en el concepto de escala que, con origen en las enseñanzas de Sócrates, a quien a su vez se la mostró la sacerdotisa Diotima, fue propio de la vida espiritual de los padres ermitaños ${ }^{26}$ y pasó a impregnar la literatura contemplativa a partir de las obras de ellos ${ }^{27}$, como demuestran algunos de estos títulos $^{28}$.

Los contemplativos carmelitas harán un uso reiterado del Cantar y también Teresa y María. Ciertamente no parece una rareza en el contexto de esta época. Frente a la insistencia de la sociedad de la Alta Edad Media por leer, comentar, interpretar y figurar el Apocalipsis, en la modernidad el texto elegido para versionarse será El cantar de los Cantares ${ }^{29}$. En la tradición que fue constituyéndose desde el siglo XII en torno a estas glosas no faltó la presencia femenina, representada en notables místicas que convierten el amor en centro de su reflexión, como Hadewijch de Amberes (Cartas y poemas de amor a Dios, 1240), Beatrice de Nazareth (Siete maneras de amor, 1268) o Juliana de Norwich (Revelaciones del amor divino, 1416). Sus escritos, auténticos Artes para un amor sin medida, pasaron a formar parte del lenguaje espiritual a través de la destacada influencia que ejercieron en el Maestro Eckhart y en Ruysbroek ${ }^{30}$. Las reflexiones sobre el amor se hallan, asimismo, en numerosos escritos espirituales con destacada presencia en el XVI hispano. Tomemos la palabra de Francisco de Osuna, autor de una de las obras que influyeron en el inicio del camino contemplativo de Teresa de Jesús. En su Tercer Abecedario Espiritual, publicado en Toledo en 1527, recogiendo el pensamiento de referentes de la mística, como Ricardo de San

25 Así, La llaga del Amor (San Juan Bautista de la Concepción, 1605), Alimento de amor (J.E. Nieremberg, 1630), Centellas de amor de Dios y su Madre (Simón de Rojas, 1653), Soledades del amor divino $\gamma$ dulces laberintos del encerramiento interior (Juan de Palafox, 1664), Llamas de amor encendido (Francisco Grau, 1687), Incendios de amor sagrado (Pedro de Calatayud, 1734), Gémidos del corazón (Pedro de Calatayud, 1736), Tálamo del amor divino. Túmulo del afecto humano. Vida para el cielo, muerte para el mundo (Francisca Bárbara Roselló, 1738), Deliquios amorosos del Divino Corazón de Jesús (José Planes, 1743), La quintaesencia del amor y compendio maravilloso de las finezas del Corazón de Jesús (Juan Antonio de Oviedo, 1749) o Las tres jornadas del cielo, vía purgativa, iluminativa y unitiva significadas en gemidos, deseos $\gamma$ suspiros ordenados en métrica (Juan de Peralta, 1749).

26 Los apotegmas de los padres del desierto constituyeron un extenso corpus con presencia notable en conventos y monasterios, DOUGLAS, Burton-Christie. La Palabra en el desierto. La Escritura $\gamma$ la búsqueda de la santidad en el antiguo monaquismo cristiano. Barcelona, Siruela, 1993. pp. 77-80.

27 HERP, Enrique. Enchiridiom vitae spiritualis $\gamma$ Scala Amoris. Salamanca, 1543.

28 De Scala Dei (Francisco Eiximenis, 1501), Scala Coeli (Alfonso de Torres, 1615), Los diez grados del amor divino del cartujo, Diego de Funes (1625), Los grados del amor de Dios en teórica y en la práctica (Juan Baptista Lisaca, 1635), Escala mística y estímulo de amor divino (Antonio Panes, 1675), Las tres jornadas del Cielo, vía purgativa, iluminativa y unitiva... (Juan de Peralta, 1749), entre otros.

29 ECO, Umberto. Il Beato de Liébana Milán, Franco María Rizzi editor, 1973. p. 5.

30 RÉGNIER-BOHLER, Danielle, Voces literarias, voces místicas, en Historia de las Mujeres II, op. cit., Pp. 473-543. 


\section{MARÍA JOSÉ DE LA PASCUA SÁNCHEZ}

Victor $^{31}$ (Arte de amar) y Hugo de Balma (Mүstica Theologia), en un intento de simplificar las fuentes de esa espiritualidad, se propone explicar el amor y con el respaldo de una cita de San Bernardo, desglosa sus clases: Dos amores hay: el uno es carnal y el otro espiritual; de los cuales se cogen cuatro maneras de amar que son amar la carne carnalmente, el espíritu carnalmente, la carne espiritualmente $\gamma$ el espíritu espiritualmente ${ }^{32}$. A mi entender, una magistral síntesis para nuestra hipótesis sobre la existencia de una profunda incardinación entre las ideas de amor místico y amor profano. Osuna, que describe la teología mística como un arte de amor ${ }^{33}$, no emplea calificativos delimitadores o excluyentes. Así, el amor es "nueva sabiduría, unión, profundidad, escondimiento, consentimiento, prohijamiento o arrebatamiento" ${ }^{34}$. En la enumeración de las distintas formas de amor de su Tercer Abecedario ${ }^{35}$, la serie de calificativos con los que lo caracteriza remite tanto a cualidades del amor humano - afectuoso, dulce, ferviente, habitual- como del divino -purgativo, iluminativo y unitivo-, en este caso las fases del amor místico $^{36}$. En todo caso diferentes cualidades presentes en la imaginería del amor de la época (insaciable, singular, ferviente, penetrativo, comunicativo, perfectivo, total, infinito) y en la que son identificables tanto algunas constantes del imaginario del amor (exclusividad, libertad, entrega, subversión, alienación, elección) como el propio sesgo que introduce la cultura de estos siglos. En el párrafo de Osuna la enumeración de características, aun observándose una clara decantación hacia lo espiritual, en ningún caso, al igual que en otros contemplativos, parecen comprenderse carne y espíritu como realidades separadas ${ }^{37}$.

31 Ricardo de San Víctor (De arrha animae) distingue tres órdenes de amor, el común a toda la creación, aquel con el que Dios ama a todos los hombres y el singular que corresponde a cada individuo, GAMARRA, Daniel O. "Hugo de San Víctor: Interioridad, Amor y Conocimiento", Revista Española de Filosofía Medieval, 2001, 8, 53-81, p. 68.

32 DE OSUNA, Francisco, Tercer Abecedario Espiritual. Toledo, 1527, en LÓPEZ, Saturnino (ed.), Místicos franciscanos españoles. Madrid, BAC, Tomo II, 2005. p. 91.

33 "Porque sólo por amor se alcanza y porque con ella se multiplica el amor", Ibidem, pp. 202-203.

34 Ibidem, p. 187.

35 Pónense, empero, muchas maneras de amor, de las cuales se podría hacer un libro por sí, ca un amor hav que se dice libre, otro natural, otro gratuito, otro seráfico, otro purgativo, iluminativo, perfectivo, habitual, sobrenatural, extático, fuerte, sabio, dulce, insuperable, insaciable, singular, movible, incesable, cálido, ferviente, penetrativo, agudo, inflexible, recto, intenso, intimo, franco, unitivo, afectuoso, tierno, espiritual, comunicativo, irremisible, indeclinable, total, infinito(...), Ibidem, PP. 202-203.

36 DE LAREDO, fray Bernardino, Subida al Monte Sión (1538) en GOMIS, Fray Juan Bautista. Místicos Franciscanos Españoles, Madrid, BAC, Tomo II, 1948. p. 3.

37 Así el Padre Ávila: “Cuanto más bestias sean los movimientos carnales, más redundarán en nuestro beneficio si los doblegamos" porque, apuntará con San Bernardo, "el fuego de la lujuria es martirio prolijo", DE ÁVILA, Juan. Avisos y reglas cristianas sobre aquel verso de David Audi Filia (edición de Juan Salas) Barcelona, 1963, pp.19-20. 
En suma, entiendo que ninguna de las características que enumera Osuna son excluyentes o particulares de uno u otro tipo de amor, sino más bien condiciones que pueden darse en él, independientemente del objeto al que se dirija. La polisemia del vocablo amor y su capacidad de denominar cualquier actividad afectiva que tiene como objeto diferentes seres le hacen aparecer en el discurso espiritual no como expresión universal de una suma de formas plurales y particulares, sino más bien como esencia, como identidad pura que se opone a lo múltiple. En esta idea del amor en la que se pierde la barrera entre el amor humano y el amor divino, resueltos cada uno conforme a su nivel en una escala de perfección pero que implica a la vez continuidad, hay dos características que deben subrayarse como propiedades fundamentales. Una es el amor como camino de conocimiento y otra es el amor como camino de sufrimiento.

\section{AMOR Y CONOCIMIENTO EN TERESA DE JESÚS}

Ambas posibilidades, la vía del amor como proceso de conocimiento y la vivencia del amor como sufrimiento, tienen presencia no sólo en estos textos sino también en la tradición clásica ${ }^{38}$ y ascética ${ }^{39}$, así como en muchos escritores espirituales que fueron fuente de inspiración para los contemplativos. El pensamiento del Padre Ávila, referente directo de Teresa de Jesús, es muy ilustrativo en la articulación entre Amor místico, conocimiento y sufrimiento. Para él ese amor supone un conocimiento particular e infuso del misterio de Cristo - la Pasión- por el que Dios le enseña el camino del amor como vía de sufrimiento. En una carta que dirige a fray Luis de Granada, su confesor y amigo, explica que, al igual que Cristo en la Pasión, el enamorado de Dios "bebe tragos de amargura por amor". Fray Luis de Granada interpretará las reglas del padre Ávila para alcanzar la contemplación (1539): la primera es lograr la compasión, el grado más bajo del amor; la segunda imitar las virtudes de Cristo, y en el tercer y último grado, "intelectual y altísimo", se obtiene el conocimiento de la Humanidad de Cristo ${ }^{40}$. También Teresa hallará en el pensamiento de la Humanidad de Cristo la inspiración para el inicio de su camino místi-

38 DE LA PASCUA, Ma José. Teresa de Jesús, cultura del yo e historia de las mujeres CALLADO, Emilio (ed.), Viviendo sin vivir en mí. Estudios en torno a Teresa de Jesús en el V Centenario de su nacimiento. Madrid, Sílex, 2016. 43-72.

39 Las palabras de la Carta VII de Hadewijch de Amberes ("Acogida e iluminada por la unidad, comprendo esta Esencia y la conozco con más claridad de lo que puedo hacerlo aquí abajo con cualquier otra cosa sensible, mediante palabras, razones o visiones") o las de la carta XX ("La naturaleza de donde procede el verdadero Amor tiene doce horas durante las cuales lo vemos partir y luego volver a sí mismo. Y cuando el Amor vuelve de este modo, reintegra en sí lo que ha asimilado en este periplo; el espíritu investigador, el corazón sediento, el alma amante") cit. en RÉGNIERBOHLER, Danielle, Voces literarias, op. cit., PP-.521-524, son hermanas de las de Teresa de Jesús.

40 DE ÁVILA, Juan, Avisos y Reglas cristianas, op. cit., Pp. 41v y 76v. 


\section{MARÍA JOSÉ DE LA PASCUA SÁNCHEZ}

$\mathrm{co}^{41}$. Por su parte, el franciscano fray Bernardino de Laredo, autor de Subida al Monte Sión, otra obra de cabecera de Teresa- ${ }^{42}$, describe la mística teología como el camino del amor; un camino que lleva del amor operativo, para principiantes, al amor desnudo, para aquellos a quienes ya aprovecha la contemplación, al amor esencial, para los que han alcanzado la perfección y al amor unitivo, para los más perfectos ${ }^{43}$. También él, para quien la puerta del amor es la puerta de la cruz, profundiza en la explicación sobre los significados de esa unión perfecta con Dios en términos de conocimiento. Citando a San Dionisio en su Mística teología, escribe que por el amor se llega a una "sabiduría escondida y celestial" que se traduce en un "conocimiento muy alto de Dios" ${ }^{4}$.

Ciertamente estas obras eran bien conocidas por Teresa de Jesús que hizo uso de ideas, explicaciones y ejemplos contenidos en ellas y, sobre todo, de sus palabras llenándolas con sus propios significados y realizando su singular interpretación sobre el amor divino. En Camino de Perfección, distingue entre dos maneras de amarse, ambas espirituales, una es "amor espiritual", en puridad, "sin que tenga que ver en él nada que toque a la sensualidad y a la ternura propias de nuestra naturaleza", y el otro es también "amor espiritual" pero que lleva consigo "la sensualidad o la flaqueza o buen amor que parece lícito como el de los deudos y amigos" ${ }^{45}$. Prosigue dedicándole el capítulo VI al "amor perfecto", el que es "puro espiritual", un amor "que no se detiene en el cuerpo" y que es el "verdadero amor", aunque otras "afecciones bajas" le hayan usurpado el nombre ${ }^{46}$. Sin embargo, hay una obra, en concreto, que tiene como objetivo el lenguaje de esta materia. Se trata de los Conceptos del amor de Dios ${ }^{47}$, o Meditaciones sobre los Cantares, su particular glosa del Cantar de Salomón. El texto está estructurado en siete capítulos, de la misma manera que su modelo, ordenado en siete poemas representativos de los 7 días de celebración nupcial de las bodas de Salomón, pero tal estructura no es seguro que estuviera originalmente en el manuscrito de Teresa pues, por lo que se sabe, se la proporcionó fray Jerónimo Gracián para publicarla. Más allá

41 TERESA DE JESÚS, (1562), Vida de Teresa de Jesús $\gamma$ algunas mercedes que Dios le hizo escritas por ella misma por mandato de su confesor, en Obras Completas de Teresa de Jesús (ed. Luis Santullano). Madrid, Aguilar, 1988, 53-251, p. 140.

42 Teresa descubrió lo que le ocurría leyéndola, Ibidem, p. 147.

43 DE LAREDO, Bernardino (fr.), Subida al Monte Sión, op. cit., p. 3.

44 "En cada tocamiento que es hecho al ánima del amor (...) es alumbrado el entendimiento tan maravillosamente que comprehende y penetra las cosas secretas y los verdaderos sentidos de las Escrituras", Ibidem, pp. 327-328.

45 TERESA DE JESÚS. Camino de Perfección, Obras Completas op. cit., 291-382., 1583. p 301.

46 Ibidem, pp. 304-305.

47 La obra fue publicada bajo el título que le dio fray Jerónimo de la Madre de Dios, Conceptos del amor de Dios, con el nihil obstat del P. Bañez obtenido en 1575. Manejo edición realizada para Obras Completas, op. cit., 487-526. 
de su composición formal, hay algunos datos que la propia Teresa ofrece y son de utilidad para aquilatar sus palabras y comentarios. Según ella misma, lo escribió de prisa, sin pensar, porque cuando leía algunos de los versos del Cantar, aún sin comprenderlos bien, su alma se movía hacia la oración contemplativa. Por estos comentarios sabemos que su escrito muestra un camino propio de amor, un camino ya recorrido y aprehendido, y lo describe porque quiere que sus hermanas se beneficien de su experiencia. También sabemos que cuando los escribió, en 1565 o $1567^{48}$ los dio a leer a su confesor y este le ordenó que los quemara; aparentemente obedeció, aunque se conservaron las copias que se habían realizado.

La idea de que la lectura del Cantar -algo muy complicado en la época por la sospecha de heterodoxia que despertaba una lectura directa e interpretativa de las Sagradas Escrituras $^{49}$-, era para ella una guía de entrada en la oración contemplativa, y por tanto en el amor, es destacable. Su interpretación del significado del Cantar y de su lenguaje también resulta de enorme interés. Recuérdese que los Cantares de Salomón, en su lectura literal, lo que muestran es el diálogo de dos amantes que se desean y se aman. Pues bien, según escribe Teresa, sólo a los simples puede escandalizar el uso de este lenguaje cuando se dirige a $\operatorname{Dios}^{50}$, ya que sólo con palabras de amor, aunque parezcan para los ignorantes muy subidas, se ama. El meollo de esta entrada en la oración inspirada por las palabras de amor del Cantar de los Cantares se localiza en los capítulos del III al VII, mientras en el primero se defiende su lectura y concretamente su lectura por parte de una mujer. En el Teresa se muestra prudente, fiel a su retórica de "santa humillación", declarándose consciente de las dificultades que las mujeres tienen para la lectura de las Sagradas Escrituras y especialmente del Cantar. Como a pesar de ello lo hace, se justifica adelantando que Dios eliminó sus temores indicándole cuanto bien le haría "algunas cosas de los Cánticos" ${ }^{51}$.

\footnotetext{
48 Hubo varias redacciones entre 1565/67 y 1576, BERTINI, Giovanni M., Interpretación de "Conceptos del Amor de Dios" de Teresa de Jesús, EGIDO, T., GARCÍA, V., GONZÁLEZ, O., (Eds.), Actas del Congreso Internacional Teresiano. Salamanca, Universidad de Salamanca-Pontificia de Comillas, 1983, vol. II, 545-556, p. 546.

49 En 1559 el inquisidor Fernando de Valdés ha dado a conocer el Cathalogus Librorum qui prohibentur (Índice) donde figuran obras de Enrique Herp, Francisco de Borja, fray Luis de Granada, fray Bartolomé de Carranza, el padre Ávila, etc. A un ruego de fray Luis de Granada al inquisidor para que le permitiese reformar su Oración a fin de sacarla del Índice, Valdés responde "que es contrario a cosas de contemplación para mujeres de carpinteros", cit., en SALAS, Juan, "Introducción", DE ÁVILA, Juan, Avisos y reglas, op. cit., p. 49.
}

50 Conceptos op. cit., p. 488.

51 Conceptos op. cit., p. 489. 


\section{MARÍA JOSÉ DE LA PASCUA SÁNCHEZ}

El amor como realidad mistérica que se desvela a aquellos que, aparentemente, no pueden entenderla, se desliza en alusiones reiteradas a esta condición, que, además, justifica el lenguaje del Cantar como lenguaje que encierra "grandes misterios" pero al que no hay que tenerle miedo ${ }^{52}$. Lo que Dios quiere dar a entender en esos versos, escribe: "Béseme el Señor con el beso de su boca" o "Mejores son tus pechos", "no lo han alcanzado a comprender grandes doctores que los han estudiado" y, aunque parezca soberbia por su parte decir que las entiende, así es ${ }^{53}$. Es, de un lado, la apropiación de un lugar común entre los espirituales de la época: la concepción del lenguaje de las Escrituras como un misterio a desvelar ${ }^{54}$, pero también es su afirmación como experta en el conocimiento de los secretos de Dios 55 .

También María se pronunciará a favor de este método de interpretación de las Sagradas Escrituras. En el Libro de recreaciones ${ }^{56}$, cuando están debatiendo sobre el mejor modo de aprender a hacer oración contemplativa, pone en boca de la más anciana y sabia de sus interlocutoras, la madre Atanasia, la manera en la que aciertan a conocer y Atanasia afirma: "el dedo de Dios toca" ${ }^{57}$. Si bien más allá de este proceso amoroso iluminativo, María como intelectual defiende el método de Orígenes, que sigue San Jerónimo, más partidario de interpretar que de traducir palabra por palabra en su versión de las Sagradas Escrituras $^{58}$. San Jerónimo, a quien ambas reconocían una indiscutible autoridad ${ }^{59}$ había indicado un orden para acceder a la Biblia, a ese lenguaje mistérico: primero el Salterio, luego los Proverbios, después el Nuevo Testamento, y sólo entonces podía abordarse la lectura del Cantar de los Cantares ${ }^{60}$, texto complejo con el que ambas se atrevieron bien pronto.

\section{Ibidem, p.488.}

53 Ibidem, pp. 489-490.

54 Perceptible también en San Juan de la Cruz, SILVESTRE, Alicia. La Traducción bíblica en San Juan de la Cruz. Subida al Monte Carmelo. Zaragoza, Universidad de Zaragoza, 2015. Pp.117-120.

55 DE LA PASCUA, Ma José. Corps humillé, corps glorieux: Paradoxe d'un langage d'auto-afirmation dans la mystique féminine (XVIe et XVIIe siécles), CICCIA, Marie-Noëlle, FAVALIER, Sylvie, IMPARATO-PRIEUR, Sylvie (dirs), Les paradoxes de l'enfermement dans l'Europe Moderne (XVIe-XVIIIe siècles). France, Espagne, Portugal. Presses Universitaires de la Méditerranée, 2018. 35-54.

56MARÍA DE SANJOSÉ. A las Charisssimas madres $\gamma$ hermanas las carmelitas descalzas. Una esclava indigna de Vuestras Mercedes, salud en el que esverdadera salud (Libro de recreaciones). Biblioteca Nacional de España (en adelante BNE), Manuscritos, 1585. Mss.3508.

57 DE LA PASCUA, Ma José. El Carmelo como jardín: del hortus conclusus al hortus theologicus en el paisaje espiritual de Teresa de Jesús y María de San José (1526-1603), Arenal 26:1, 2019. pp. 35-65.

58 DE LA PASCUA, Ma José. La carmelita María de San José (Salazar), una priora rebelde, ATIENZA, Ángela(ed.), Mujeres entre el claustro y el siglo. Autoridad $\gamma$ poder en el mundo religioso femenino (siglos XVI-XVIII). Madrid, Sílex, 53-82, 2018. PP. 74-75.

59 Ibidem, pp. 67-68.

60 SILVESTRE, Alicia. La Traducción bíblica op. cit., 2015. pp. 121-122. 
En el Capítulo II de los Conceptos, Teresa realiza una serie de avisos a sus hermanas del Carmelo sobre ese camino de amor, en el que no basta quedarse a los pies del monte ${ }^{61}$, sino llegar a la cumbre, es decir, a un amor total ${ }^{62}$. De nuevo hallamos aquí una lectura interpretativa muy propia para una carmelita de las escalas o grados del amor. En los capítulos siguientes pasa a describir como es esa "oración de quietud y de unión", cuando el alma se "engolfa" en la suavidad y el sosiego que le depara la "amistad" con su esposo.

La escritora parece advertir que el lenguaje del amor es universal ${ }^{63}$. Asumiendo varias de las figuras que Roland Barthes considerará habituales en la expresión del amor: su condición de experiencia inefable, mistérica e inenarrable ${ }^{64}: 11$ ena de "misterios" ${ }^{65}$ y de vivencias

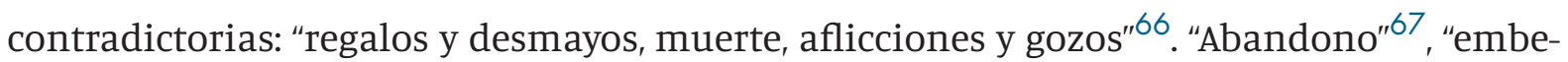
bimiento" 68 , "engolfamiento"69 , "borrachez divina" 70 , "embriaguez celestial" 71 , "santo desatino" $^{\prime 72}$ o "paraíso de los deleites" ${ }^{\prime 3}$, son algunas de las expresiones que utiliza. Palabras que retoma en la descripción de la boda mística, reiterada en otros escritos. En Las Moradas, Teresa habla sobre ese "lugar de gracia" donde el alma conoce al esposo y el "juego del amor", que es un "incendio", la transporta a un estado de "arrobamiento", "éxtasis" o "rapto", "que todo es uno"74.

Más allá de la espectacularidad de los éxtasis o raptos, de la "merced del dardo" tan descrita y reiterada en la literatura y el arte, la unión amorosa así representada por ella es un ca-

61 El monte tiene una profunda simbología en la espiritualidad contemplativa y, especialmente, en el Carmelo. Contamos con varias representaciones gráficas de ese camino de ascenso de la mano de San Juan de la Cruz, entre ellas la de 1578, en la que se parte de una herencia espiritual común entre los místicos, la alegoría de la Montaña Santa como escalera de virtudes SILVESTRE, Alicia. La Traducción bíblica op. cit., 2015. p. 111.

62 Según explica, a la esposa no le basta con decir "béseme" sino "béseme con beso de su boca", TERESA DE JESÚS, Conceptos, op. cit., p. 496.

63 “¿Por qué no habíamos de decir a Dios esto?", el alma abrasada de amor no quiere sino decir estas palabras, porque estas y otras semejantes que están en los Cantares, las dice el amor. TERESA DE JESÚS, Conceptos, op. cit., p. 489. 64 DE LA PASCUA, Ma José. Regulación de los afectos y cultura del amor, op. cit., 2015. pp. 248-251.

65 TERESA DE JESÚS, Conceptos, op. cit., cap. I

66 Ibidem

67 Ibidem, cap. IV, 503 y ss.

68 Ibidem, cap IV.

69 Ibidem, cap. IV, y p. 507.

70 Ibidem, cap. IV.

71 Ibidem

72 Ibidem

73 Ibidem, cap. VI.

74 Entonces el alma está "fuera de sus sentidos", porque Dios "no quiere estorbos" para mostrarle "el reino que ha ganado", TERESA DE JESÚS, Castillo interior o Las Moradas (1577), en Obras Completas, op. cit., 383-485, p. 441 y ss. 
mino de conocimiento teológico ${ }^{75}$. Aunque como se ha destacado la mística de Teresa de Jesús es un compendio de la espiritualidad de la época en la versión contemplativa y ella reivindica el papel de los libros en su propia búsqueda del camino ${ }^{76}$, la fuente principal de conocimiento según escribe es la experiencia, una experiencia de comunicación directa con Dios ${ }^{77}$. El entendimiento como discurso racional o lógico, tal y como sucede en toda la mística occidental y oriental, estorba a las exigencias de ese amor total que no es razonable y exige una fe ciega, adoptando la versión clásica de amor como locura ${ }^{78}$. Es el propio cuerpo, en el que Dios se manifiesta a través de sus señales, el que advierte del amor alcanzado, puro deleite que embriaga y emboba, que hace olvidar al mundo y sus criaturas, que supera todos los placeres terrenales y que también es sabio y buen maestro, suave y no violento. Su naturaleza es tal que la jerarquía entre esposo-esposa, propia del contexto patriarcal en el que ella vive, se invierte ${ }^{79}$. Teresa no es una ignorante y sabe poner nombre a todo esto que le sucede: es "mística teología". Es conocimiento teológico aunque el entendimiento esté, en esos momentos, como suspendido, porque está "espantado de lo mucho que entiende $^{\prime \prime 80}$. Es entonces cuando Dios se comunica con ella a través de visiones imaginarias e intelectuales ${ }^{81}$ que le suponen "grandes mercedes" ${ }^{82}$, es decir una comprensión de los secretos de la fe y de una verdad que no ha sido revelada, además de un gran "gozo interior" y un "profundo desasimiento" hacia el mundo ${ }^{83}$. Las visiones que tiene en los momentos de unión con Dios son mensajes que le producen consuelo - como aquella vez que vio en el Cielo a sus padres ${ }^{84}{ }_{-}$, señalan a los elegidos por Dios entre sus amigos y correligionarios ${ }^{85}$ o auguran el bien para aquellos por quienes ha intercedido ${ }^{86}$. También ella es objeto de favores que son de dos tipos, aquellos en que Dios la señala como una elegida: “Ya eres mía

75 Así lo cantará Lope en sus Rimas sacras “Herida vais del Serafín, Teresa, (...)/ Con razón vuestra ciencia el mundo admira", LOPE DE VEGA, Rimas sacras, [en línea], www.cervantesvirtual.com. [consulta: 13 de septiembre de 2020]

76 Recomienda a las preladas algunas obras que considera "alimento fundamental para el alma", TERESA DE JESÚS. Vida de Teresa de Jesús, en Obras Completas, op cit., 1562. pp. 53-251.

77 TERESA DE JESÚS, Camino de Perfección, op. cit., p. 139.

78 "que la misma fuerza del amor le ha quitado el entendimiento para poderle más amar", Ibidem, p. 510.

79 TERESA DE JESÚS, Camino de Perfección, op. cit., p. 344.

80 TERESA DE JESÚS, Vida, op. cit., p. 87. Teresa se inspira la Subida al Monte Sión, op. cit., cap. 41.

$81 \mathrm{El}$ lenguaje a través de visiones y la distinción entre ellas -corporal, imaginaria e intelectual-, habitual en la mística, está en Teresa, aunque prudentemente matizado: las suyas, señala, no son corporales, Vida, op. cit., p.168.

82 Desde 1569 Teresa lleva un cuaderno donde refiere las mercedes recibidas al que llama Cuentas de conciencia.

83 TERESA DE JESÚS, Vida... op. cit., p. 87 y 230-231.

84 Ibidem, p. 239.

85 Ibidem, p. 232.

86 Ibidem, pp. 237-239. 
y yo soy tuvo"$^{\prime 87}$ y aquellos otros que le procuran conocimiento sobre los misterios de la $\mathrm{fe}^{88}$. Desde la visión del mundo ${ }^{89}$, hasta aquella otra en la que se le representa la subida al cielo de la virgen ${ }^{90}$, o el conocimiento del misterio de la Santísima Trinidad, tanto en versión abstracta como en representación imaginaria 91 , integran una "comprensión" tan completa de las cosas de Dios "que no hay teólogo con quien no me atreviese a disputar de la verdad de estas grandezas" 92 .

\section{EL AMOR COMO CAMINO DE SUFRIMIENTO EN MARÍA DE SAN JOSÉ}

No es que en Teresa de Jesús esta experiencia esté ausente, muy al contrario, pero en María de San José es leiv-motiv de sus escritos, de ahí que la elija para profundizar en esta perspectiva. También ella, hija predilecta de Teresa, compañera y amiga y a quien la fundadora del Carmelo descalzo deseaba como cabeza y guía del mismo a su muerte, hará su propio comentario del Cantar. María es una excelente poetisa, generalmente escrita en versos cultos de arte mayor ${ }^{93}$, y aunque se han conservado sólo unos pocos poemas, los que se conocen responden a la temática amorosa tradicional en la mística: la búsqueda del amado y el encuentro místico ${ }^{94}$ En sus poemas es perceptible el lenguaje inflamado usual entre los contemplativos como en Ansias de amor ${ }^{95}$, paráfrasis libre del Cantar de los Cantares, que data de 1567, dos años después de la aparición de la traducción que hizo del Cantar fray Luis de León y de las Meditaciones sobre el Cantar que salieron de la pluma de Teresa de Jesús. Respecto al resto de su poemario, escrito en Lisboa ${ }^{96}$, muestra el espíritu combativo de María. Su obra Resumptas ${ }^{97}$ (1593-1595) es

\section{Ibidem, p. 243.}

88 Castillo interior, op. cit, p. 442.

89 Ibidem

90 Ibidem, p. 245.

91 Ibidem, p 472.

92 TERESA DE JESÚS, Vida, op. cit., p. 246

93 MORUJÄO, Isabel, María de San José (Salazar) OCD, fundadora del primer Carmelo Descalzo femenino en Portugal, Revista de Espiritualidad 63 (2004), 177-211, 204-205.

94 MANERO, Ma Pilar. On the Margins of the Mendozas: Luisa de la Cerda and María de San José (Salazar), NADER, Hellen, Power and Gender in Renaissance Spain. Eight Women of the Mendoza Family, 1450-1650. University of Illinois Press, 113-123, 2004. p. 121.

95 Búsqueda del amado, encuentro final, unión mística y el tema del desprecio del mundo, MANERO, Pilar, Exilios y destierros en la vida y obra de María de Salazar, 1616, Anuario de la Sociedad Española de Literatura General $y$ Comparada (1988), pp. 51-59.

96 MANERO, Ma Pilar, On the Margins op cit., P. 122.

97 Resumptas de la Historia de la fundación de los descalzos y descalzas carmelitas que fundó S. Teresa de Jesús, nuestra madre (...) se cuentan algunos trabajos que se pasaron (...). En el original de María de San José precede a esta Historia de la Fundación una introducción, constituida por material diverso - sonetos, elegía, redondillas- y lo que la escritora llama "Ramillete de mirra". BNE. Manuscritos (Ms 2176). 
también de este periodo de madurez y en ella realiza una historia de las descalzas y del periodo conflictivo vivido en el Carmelo descalzo a la muerte de su fundadora. Dicha obra la inicia con un Ramillete de Mirra que abre con la glosa de un versículo del Cantar ${ }^{98}$. En la misma, a modo de introducción, María explica que para las monjas seguir al esposo, amar a Dios, es una corona de espinas. Comienza dirigiendo a sus hermanas de religión, a modo de pregunta retórica, el desafío de identificar qué tipo de amor es el que vivirán. ¿Acaso pensáis que ese amor es regalo y consuelo?, ¿Qué basta con poner al amado entre vuestros pechos para gozar de él con dulzura? ¡Desengañaos!, responde; si pensamos así vamos erradas. Porque este esposo no es de la misma condición de Adán, no se puede ir a comer con él la manzana dulce; no, es Cristo Jesús "que paga la dulzura con la amargura y el tormento de la Cruz". Su abrazo es un "abrazo amargo" y el camino a recorrer con él está lleno de "tribulaciones" y "sufrimientos" 99 . No obstante, María invita a sus hermanas carmelitas a sufrirlos con alegría porque Cristo es un "esposo de sangre"; en el matrimonio espiritual "las galas son escarnios", "las honras, oprobios", los "regalos, azotes", sus "músicas blasfemias", "su manjar, hiel", su "corona, espinas" 100 . Aun así, no hay en la tierra gusto que se iguale este ${ }^{101}$. No hay duda que, en su concepción del amor, María está vertiendo su propia experiencia, la experiencia de una "esposa" perseguida. Su historia de las descalzas va a recoger, precisamente, esos años de persecución que ha sufrido por defender las Constituciones que recogían el espíritu de la reforma descalza impulsada por Teresa de Jesús y a manos del que fue Provincial de la orden entre los años 1585 y 1594, el P. Nicolás de Jesús María (Doria). La idea de amor como sufrimiento se vincula así a su vida en el Carmelo, pero este sufrimiento reivindicado como muestra de amor total está también permeado de su espíritu rebelde y combativo. Y no sólo porque haya causado su defenestración, sino por la interpretación que ella da a al mismo: la verdadera amante de Cristo, escribe, sabe que la tribulación y el oprobio son el santo y seña del amor divino. Por eso advierte a sus hermanas: no os dejéis engañar, aún más ¡disfrutadlo! ${ }^{102}$. En otro tono y de forma aún más personal había descrito su ánimo ante las que había padecido en el Libro de recreaciones, cuando a la pregunta de una de sus interlocutoras simbólicas Justa, sobre si sufrió cuando la perseguían injustamente, responde negativamente. A la insistencia de Justa en

98 "Ramillete de mirra es mi amado: para mi pondréle entre mis pechos", Resumptas op cit. fol. 1.

99 Ibidem, fols. 1v-2.

100 Ibidem.

101 Ibidem.

102 “¿Adónde, por ventura, se halla la verdadera sabiduría sino en la pena y la Cruz?", Ibídem, fol. 3v. 
su interrogatorio concluye por boca de Gracia: “Créeme que en mi vida estuve más alegre ni con mejor ánimo" ${ }^{103}$. En Ramillete de mirra la seguridad y el orgullo por el camino que ha seguido se convierte en desafío y en un párrafo vibrante reta a los que la persiguen a que sigan haciéndolo.

“Desampárenme los amigos, $\gamma$ esos que en otro tiempo me favorecían $\gamma$ hon raban, esos me atribulen $\gamma$ deshonren; $\gamma$ aquel que siempre amé $\gamma$ tuve por padre, $\gamma$ de oficio le toca defenderme, ese me desampare $\gamma$ aflija. Infámenme en lo que más es infamia, crean de mí que he perdido lo que más guardo y estimo; quítenme las insignias de honra, pregónenme por descomulgada y perjura, (...) ¿Qué me toca o que me va, que por tal sea tenida de los que hov son, $\gamma$ mañana se acaban, de aquellosque a símismos no pueden honrar? ¿Quéhonra oquedeshonra me pueden dar? Llámenme a ser reina en un reino eterno, con un esposo en cujas manos está la vida $\gamma$ la muerte, $\gamma$ la honra $\gamma$ la deshonra ¿ү tengo de ser tan ciega, que en el camino me detenga, procurando honra del villanaje $\gamma$ aldea de este mundo?"104.

La trascripción de este largo párrafo merece la pena porque retrata muy bien la personalidad de esta carmelita rebelde, para la que una honra de "villa y aldea", la de este pequeño mundo, no significa nada. No tiene miedo a señalar a sus perseguidores, ni siquiera al padre Doria que gobierna La Consulta y la orden y confiesa que sale reafirmada de estos "trabajos" porque ni aún en los momentos más delicados ha perdido la seguridad en lo que hacía. Tampoco su espíritu combativo se ha visto menoscabado y demuestra con sus palabras que ha salido indemne de la persecución. Sus escritos, repetirá en varias ocasiones, tienen como propósito contar la verdad, la verdadera historia de las descalzas y advertir a sus hermanas de la naturaleza del camino que han emprendido: el matrimonio con Cristo ${ }^{105}$. Por eso pide a Dios que le mande otra buena andanada de "tribulaciones", de esas que iluminan el camino y son como "manojo de mirra" entre los pechos ${ }^{106}$.

Como podemos apreciar el lenguaje del Cantar está en las dos, pero cada una lo adecúa a su experiencia y conocimientos. María juega aquí con las palabras y sus significados aludiendo

103 DE LA PASCUA, Ma José, La carmelita María de San José, op. cit., p. 57.

104 MARÍA DE SAN JOSÉ, Resumptas, op. cit., fols. 4-5.

105 Ibidem, fol.8

106 Ibidem. 


\section{MARÍA JOSÉ DE LA PASCUA SÁNCHEZ}

a la mirra, arbusto cuya resina posee un aroma embriagador, aunque es de sabor amargo y tiene como característica destacada sus espinas. Su significado está cargado de simbolismo en el lenguaje bíblico representando la vulnerabilidad de la naturaleza humana y, al tiempo, la trascendencia de su destino. Buena conocedora de las plantas y sus propiedades, en ella la elección de esta imagen del amor como "ramillete de mirra" está hecha a conciencia y orientada en la misma lógica que preside este prólogo, así como los tercetos que también figuran en la Introducción y que comienzan con En el nombrado puerto de Ulisea ${ }^{107}$.

A pesar de lo que pudiera parecer, la aceptación del sufrimiento como camino obligado de las que eligen el "Amor sagrado", no hay conformismo en sus palabras. Ella se rebela contra el poder que quiere apartarlas del camino elegido y torcer el proyecto de Carmelo que imaginó la madre común, Teresa de Jesús. Toda su vida religiosa la percibe como una oposición a esos intentos de apartarla del espíritu de la reforma carmelita, materializado en sus constituciones y reglas. Así, su lucha contra los que querían arrebatar a las prioras su función de guía en los monasterios - problemas que tiene cuando es priora en Sevilla, 1575- o el largo enfrentamiento con la política del padre Doria en sus intentos de someter a las monjas (1584-1594), que pagó con el ostracismo y la cárcel ${ }^{108}$. A pesar de ello, sigue defendiendo su actuación y su visión de las cosas en sus escritos, en cartas privadas que dirige a las hermanas ${ }^{109}$, en los consejos que da a las prioras ${ }^{110}$, en definitiva, en un magisterio vivo y escrito con el que trata de sortear los obstáculos con los que las mujeres del Carmelo se tropiezan.

En los tercetos En el nombrado puerto de Ulisea ${ }^{11}{ }^{1}$, desde monasterio de San Alberto (Lisboa), denunciará sin tapujos la situación de las carmelitas descalzas ("deas consagradas a la sublime diosa del Carmelo") ${ }^{112}$, desde la muerte de Teresa de Jesús. La ("infernal tormenta") ${ }^{113}$ desatada contra ellas con el objetivo de torcer su proyecto ${ }^{114}$. Su consuelo es que en ella "no habrá mudanza" y, aunque con el dolor la voz "le va faltando", al contemplar lo perdido "el mismo

\section{Resumptas, op. cit., fol VIII.}

108 DE LA PASCUA, $M^{\mathrm{a}}$ José. Poder y guerra en la familia carmelita: el testimonio de una voz silenciada (María de San José-Salazar, 1578-1603), SANCHEZ-MONTES, F. LOZANO, J.J., JIMENEZ, A. (eds.), Familias, Élites y redes de poder cosmopolitas de la Monarquía Hispánica en la Edad Moderna. Granada, Comares, 2016. pp. 219-251.

109 MARÍA DE SAN JOSE, Carta que escribe una pobre $\gamma$ presa descalza (1593)

110 MARÍA DE SAN JOSÉ, Consejos que da una priora a otra (1590-1592)

111 Resumptas, op. cit., fol VIII

112 Ibidem, fol. IX -en el manuscrito aparece la palabra "ninfas" tachada y sustituida por "deas"-

113 Ibidem, fol. VIII.

114 Ibidem, fols. IXv-X. 
dolor la va esforzando" 115 en recuperar lo que tuvieron: el Carmelo. Ese "fértil prado", como era, cuando Teresa "como atenta pastora", lo cuidaba y cuando el ganado estaba bien apacentado ("Libre pacía por el fresco prado,/Porque no se atrevía el lobo fiero/Acometer ante ella su ganado") $^{116}$."Aciago, día" ${ }^{17}$, escribe, aquel que la muerte apartó a Teresa de su rebaño. Entonces, a diferencia de la situación presente ${ }^{118}$ en el Carmelo reinaba la "ley del amor" porque "el amor anda rindiendo, /Al poderoso, fuerte y grande rey" ${ }^{19}$ y la "Dulce pastora" los mantenía en "paz y amor perpetuo" ${ }^{120}$. La descripción del Carmelo en los tiempos de lucha por someter a los conventos femeninos es valiente. María de San José no se priva de señalar lo que está haciendo con la reforma de Teresa de Jesús esa "bestia fiera" -La Consulta con el padre Doria a la cabeza- que pinta con malos colores la pretensión de libertad de las monjas y persigue a las que la defienden. Concluye, sin embrago, señalando que no tiene miedo ni a los pleitos ni a las acusaciones: “No temeré por cierto defenderlo/Y por culpada quiero ser tenida./Pues que lo soy, yo quiero parecerlo." ${ }^{121}$

El tema se repite en otras poesías y en sus obras en prosa, porque este asunto es argumento fundamental de sus escritos, pero lo mostrado permite extraer unas conclusiones. La primera de ellas, y en relación con la fuerte carga autobiográfica de los escritos de ambas, el valor de los mismos como fuente para el análisis del amor y sus vivencias en la España del XVI y su interés especial al tratarse de prácticas femeninas. La segunda tiene que ver con las diferencias entre estas dos escritoras. Es obvio que comparten una cultura común y la tópica amorosa que corresponde a la época, pero también lo es que la usan de forma diferente y que estas diferencias tienen que ver tanto con el carácter y las vivencias de cada una como con el distinto tipo de formación recibida. Sus escritos, por tanto, permiten romper la tendencia a esencializar la práctica escrita, especialmente habitual cuando se trata de temas amorosos y se enfatiza el peso de los tópicos sin atender a los rasgos socioculturales, biográficos y experienciales. Teresa ha recibido una formación general buena, si se la compara con la que recibían las

115 “Y aunque la menor soy determinada/estoy a padecer de cualquier modo/Que aunque me tienen muda, no mudada/ni mudarán jamás..." (María alude a condena al silencio que pesó sobre ella), Ibidem, fol. XIV.

116 Ibidem, fol. XIv.

117 Resumptas, op. cit., fol. IX v.

118 "Mira este tu rebaño que se pierde/Con un grave dolor, que es insufrible./Mira que se ha secado el prado verde (.../ Mira está tu manada desparcida,/Mira la cumbre toda destrozada,/La res aquí y allí despavorida/(...) Lo que salud nos era, es ya ponzoña;/Ya se pasó aquel tiempo venturoso,/ya no suena rabel, ya no hay zampoña/Do cada cual mostraba ser dichoso/ Ya no hay sino tristeza en cada parte,/Ya no hay sino balido doloroso"(Ibidem, fol. XIII).

119 Ibidem, fol. XII.

120 Ibidem.

121 Ibidem, fol. XVIv. 


\section{MARÍA JOSÉ DE LA PASCUA SÁNCHEZ}

mujeres de su tiempo. Educación que ella ha completado con una formación espiritual autodidacta, dirigida hacia las corrientes más renovadoras del momento. En cambio, María ha disfrutado de una formación esmerada propia de los ambientes nobiliarios en los que ha vivido y con los que ha tenido relación, alrededor de varias mujeres cultas de la época (Luisa de la Cerda y otras mujeres de la Casa de Mendoza y Silva). Ambientes en los que se valoraban los estudios humanísticos y muy sensibles, también, a las tendencias espirituales vinculadas a las reformas. Además a María le gusta ejercer de intelectual ${ }^{122}$. En ese sentido, compartiendo el proyecto común y colectivo de la descalcez femenina carmelita, Teresa comprende su individualidad en la experiencia inefable del amor divino. María, aunque sabemos por la correspondencia con Teresa y por sus escritos que también vive el amor unitivo que traslada a algunos poemas místicos, parece reconocerse mejor y crecerse en la lucha que ha mantenido y mantiene por la defensa del proyecto de vida en el Carmelo que Teresa de Jesús fundó. Aunque, como hace Teresa, defienda el conocimiento que ellas adquieren de la experiencia amorosa con Dios, enfatiza la dimensión del amor a Dios como sufrimiento, articulando la misma a su quehacer en el mundo y a su experiencia personal en la dimensión más pública.

En cualquier caso, a través de ellas y sus escritos, es posible el análisis en clave femenina de las múltiples vivencias adheridas al llamado "amor sagrado". Ambas mujeres se mostraron conscientes de las limitaciones que la ideología de género oponía a su actividad social y cultural y a su experiencia personal y ambas las cuestionaron con sus prácticas de vida y escritura. Teresa, aunque no consigue engañar a todos, envuelve su vocación de guía espiritual en un momento de dificultades religiosas y su afirmación como experta teóloga en una retórica prudente. Aleccionará a María con frecuencia sobre los peligros de su lenguaje directo, y aunque María, ya cercana su muerte comprenderá que ha sido una táctica contraproducente, ella que no se rinde por amenazas, sino solo por amor ${ }^{123}$, defenderá su causa hasta el final. Y su causa es también la de las mujeres. En cualquier caso, su escritura, atravesada de vivencias, muestra como los discursos amorosos que confluyen en la modernidad son utilizados de forma creativa en la lectura de las experiencias personales.

122 DE LA PASCUA, Ma José, María de San José una priora rebelde, op. cit., pp. 59-76.

123 MARÍA DE SAN JOSÉ, Libro de recreaciones, op. cit., p.20. 